\title{
Light, Temperature, and Moisture Effects on Apothecium Production of Sclerotinia sclerotiorum
}

\author{
P. Sun and X. B. Yang, Department of Plant Pathology, Iowa State University, Ames 50011
}

\begin{abstract}
Sun, P., and Yang, X. B. 2000. Light, temperature, and moisture effects on apothecium production of Sclerotinia sclerotiorum. Plant Dis. 84:1287-1293.

The purpose of this study was to quantify the effects of light, moisture, and temperature on apothecium production of Sclerotinia sclerotiorum. Sclerotia were placed in sand beds in crispers and exposed to two light intensities. For each light intensity, sclerotia were subjected to five temperature levels and three moisture levels. The results showed that the optimal temperature and temperature range for germination of sclerotia were affected by both light intensity and the moisture level of the sand. At light intensity of 80 to $90 \mathrm{~mol} \mathrm{~m}^{-2} \mathrm{~s}^{-1}$ (low light intensity treatment), the optimal temperatures were in the range of 12 to $18^{\circ} \mathrm{C}$ regardless of moisture level. At light intensity of 120 to $130 \mathrm{~mol} \mathrm{~m}^{-2} \mathrm{~s}^{-1}$ (high light intensity treatment), the optimal temperature was shifted to $20^{\circ} \mathrm{C}$ when the soil moisture level was high. Under high light intensity, only a few days were needed for initials to develop into apothecia. Under low light intensity, several weeks were needed for initials to develop into apothecia. The frequency with which initials developed into apothecia was high under high light intensity $(80 \%)$ but low under low light intensity. The initials produced at low light intensity and high temperature $\left(25\right.$ to $\left.30^{\circ} \mathrm{C}\right)$ were thinner and longer. The apothecia also were smaller at low light intensity than those produced at high light intensity at any temperature. The periods for apothecium production were longer under lower temperature treatments. The relationship between apothecium production and degree days was analyzed. Apothecium production began at about 160 degree days and ceased at about 900 degree days at high light intensity. However, production began at about 760 degree days and ceased at 1,720 degree days at low light intensity. Nonlinear regression equations which describe the relationship between cumulative formation of apothecia and degree days were highly significant. The deviation between the observed value and the predicted value increased as degree days increased.
\end{abstract}

Additional keywords: carpogenic germination, disease prediction, Sclerotinia stem rot, soybean

Sclerotinia sclerotiorum (Lib.) de Bary, which causes Sclerotinia stem rot of soybean, has many host crops (2). The fungus produces sclerotia as survival structures and spreads from field to field by internally infected seeds (29) and sclerotia mixed with seed (7). During a growing season, sclerotia in infested fields germinate by producing mycelia or apothecia. Infections are initiated by mycelia arising from the sclerotia or by airborne ascospores produced in apothecia. Ascospores are the primary inoculum for epidemics in many crops $(3,4,13,15-18)$. In Sclerotinia rot, ascospore production by apothecia is the key event for epidemics to occur (1921,23).

Corresponding author: X. B. Yang

E-mail: xbyang@iastate.edu

Journal paper J-18547 of the Iowa Agricultural and Home Economics Experimental Station, Ames. Project 3384 supported by Hatch Act and State of Iowa funds.

Accepted for publication 22 August 2000.

Publication no. D-2000-1005-02R

(c) 2000 The American Phytopathological Society
Sclerotinia stem rot of soybean is an emerging production problem in the northcentral region of the United States. Before the 1990s, the disease had localized epidemics in Michigan, Minnesota, and Wisconsin (7). It was ranked 12 th in disease losses in U.S. north-central soybean production in 1990 (6). Since 1990, this disease has become widespread in the northcentral soybean production region of the United States for reasons yet to be determined. In a survey conducted in 1994, the disease ranked second after soybean cyst nematode (Heterodera glycines) as a leading cause of yield loss in the north-central region (26). In Iowa, the disease was not recognized as a significant problem until 1992, when severe outbreaks occurred in major soybean production areas of northern and central Iowa. Further outbreaks in these areas occurred in 1994 and 1996. The disease was in epidemic proportions again in northern Iowa in 1997 (27).

Environmental conditions are very important in producing epidemics of the disease. Previous studies showed that a wet and cool midsummer is favorable for development of the disease $(4,5)$. Disease forecasting models that use environmental variables, such as moisture, temperature, and light, are not available for this disease. It is necessary to quantify the interaction between environmental factors that affect life cycle of the fungus in order to make predictions of the disease. Currently, one management option for this disease is the use of fungicides. The relatively high cost of fungicides requires timing of applications near the production of apothecia for maximum benefit. A reliable forecast of Sclerotinia stem rot occurrence could help make decisions of when to apply the chemicals to soybeans grown in fields infested with sclerotia.

Investigations have been conducted on the interaction between apothecia production of sclerotia of S. sclerotiorum and environmental factors, which include weather and soil conditions $(8-10,16,18$, 22-25). Light, temperature, and moisture are considered the three most important factors for carpogenic germination of sclerotia of $S$. sclerotiorum $(2,12)$. Field and laboratory studies on the effects of temperature and moisture on apothecia production of the fungus also have been reported $(1,8-10)$. However, there is no report on quantification of the effect of light intensity on production of apothecium. Our observations indicate that light intensity may interact with soil moisture and temperature to affect apothecia production in soybean fields, which has not been reported previously. At present, there are no mathematical models that use temperature, moisture, and light as variables to project apothecia production. Studies on the effect of temperature, moisture, and light on apothecia are needed for the prediction and management of the disease.

In this study, growth chamber experiments were conducted to quantify the effects of light, temperature, and moisture on apothecium production of sclerotia of $S$. sclerotiorum. We also used the degree day concept and experimental data to develop models for the apothecium production. Part of this research was previously reported (21).

\section{MATERIALS AND METHODS}

Collection and conditioning of sclerotia. The sclerotia used were collected from a soybean field planted to cv. Pioneer 9294 near Gilmore, IA that had a high severe infestation of sclerotia of S. sclerotiorum. In autumn, sclerotia were collected by removing the sclerotia from harvested soybean seeds on a gravity table. Only sclerotia of similar size, approxi- 
mately 12 to $14 \mathrm{~mm}$ in length and about 3 $\mathrm{mm}$ in diameter, were used for the experiments. Thirty-two sclerotia were placed on three layers of a sterile paper towel saturated with $8 \mathrm{ml}$ of sterile distilled water and placed in a sterile glass petri plate. Plates containing 32 sclerotia each were then sealed with parafilm and placed in a refrigerator at $4.5^{\circ} \mathrm{C}$ for preconditioning for 2 months. In each experiment, plates were chosen at random and the sclerotia were mixed together to eliminate any differences in preconditioning among plates. The experiments were conducted in 1996 and 1997.

Experimental design. Factorial experiments were conducted to determine the effects of light intensity, temperature, and moisture on the germination of sclerotia.
Effects of two light intensities (high and low) were examined. For each light intensity, preconditioned sclerotia were subjected to five temperatures and three moisture levels. A 31-by-23-by-11-cm crisper containing $4 \mathrm{~kg}$ of sterilized sand was used for each temperature-moisture combination. Fifteen crispers per light intensity were divided into five temperature groups and placed in a growth chamber (PGW36/Conviron). In each group, water was added to the sand, making three moisture levels. Sixteen sclerotia were placed on the surface of the sand in each crisper. The temperatures were controlled by stepless temperature controllers (Thermolyne Type 45500) and heating tapes (Thermolyne/Briskheat 122-by-1.3 $\mathrm{cm})$. The chamber temperature was set to
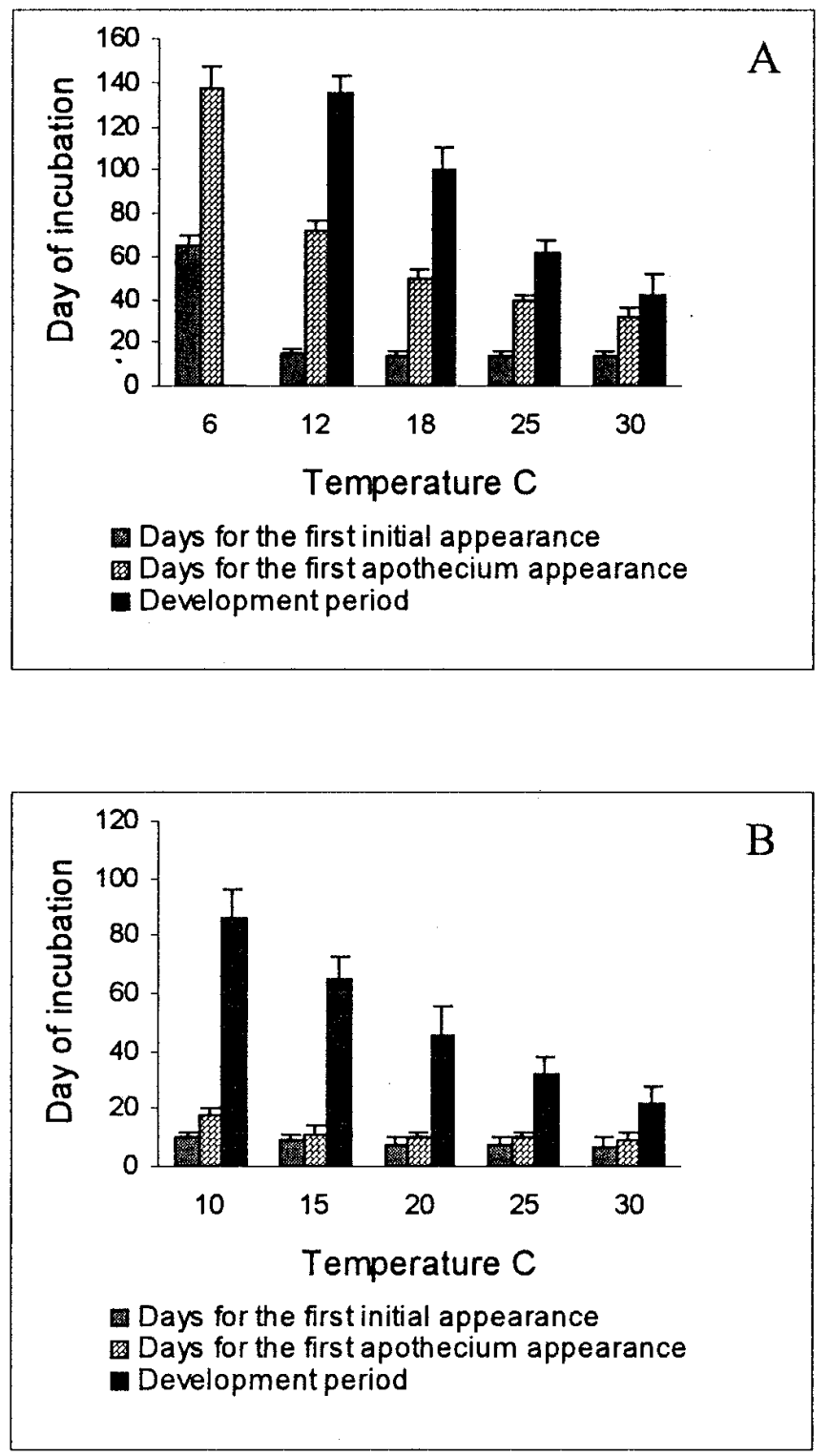

Fig. 1. Effects of light, temperature, and moisture on three variables of carpogenic germination of sclerotia of Sclerotinia sclerotiorum: day of the first initial appearance, day of the first apothecium appearance, and development period (first day to day of final apothecium appearance) at (A) lower and (B) higher light intensity. The experiments at low light intensity were terminated at 150 days. At that time, only a few initials became apothecia at $6^{\circ} \mathrm{C}$. Development period at that temperature level was not calculated. Values are the means plus the standard error of the means.

equal the lowest temperature group of crispers. Crispers of other groups were wrapped by heating tapes and fastened by adhesive tape. The crispers in each temperature group were connected to a controller to maintain a constant temperature. The three moisture levels were I, II, and III. In level I, free water could be seen on the surface of the sand. In level II, the sand was near saturation but without free water on the surface. In level III, the amount of water was $50 \%$ of level II. Moisture levels I and II corresponded to 700 and $670 \mathrm{ml}$ of water per crisper. Moisture level III used $335 \mathrm{ml}$ of water per crisper.

The growth chambers were provided with fluorescent light $14 \mathrm{~h}$ per day. In the low light intensity treatment, the light intensity ranged from 110 to $120 \mathrm{~mol} \mathrm{~m}^{-2} \mathrm{~s}^{-1}$ at the covers of the crispers and ranged from 80 to $90 \mathrm{~mol} \mathrm{~m}^{-2} \mathrm{~s}^{-1}$ inside the crispers. In the high light intensity treatment, the light intensity was between 160 and $190 \mathrm{~mol} \mathrm{~m}^{-1} \mathrm{~s}^{-1}$ at the cover of the crispers and 120 to $130 \mathrm{~mol} \mathrm{~m}^{-2} \mathrm{~s}^{-1}$ inside the crispers. The experiments at the different light intensities were repeated once. Each crisper contained one thermometer and the temperatures were monitored daily for all treatments. At low light intensity, the five measured temperatures were $6,12,18,25$, and $30^{\circ} \mathrm{C}$, and at high light intensity they were $10,15,20,25$, and $30^{\circ} \mathrm{C}$. There were variations in temperatures. In high temperature treatments $\left(25\right.$ and $\left.30^{\circ} \mathrm{C}\right)$, the standard error (SE) was $1^{\circ} \mathrm{C}$ and, in the low temperature treatment, SE was $0.5^{\circ} \mathrm{C}$. After 150 days of the low light experiments, only a few initials turned to apothecia at $6^{\circ} \mathrm{C}$. It would have taken several more months to complete the generation for this treatment; therefore, the experiments were terminated at 150 days.

Data collection and definition of variables. A sclerotium was considered germinated when at least one initial was observed. Data were collected every 2 days after first appearance of initials in a crisper. The number of live and dead initials and apothecia on each sclerotium were counted. When the initials or apothecia became wilted, they began to show rot appearance within $24 \mathrm{~h}$ in high temperature treatments $\left(25\right.$ or $\left.30^{\circ} \mathrm{C}\right)$. It took about 2 days for rot appearance to occur at lower temperature treatments. Therefore, an initial or apothecium was considered dead when their tissues appeared rotted. Subsequent to counting, dead initials and apothecia were removed to prevent counting duplications. Three measurements of apothecia production for each moisture-temperature-light intensity combination were also collected. These measurements consisted of day of the first initials appearance, day of the first apothecia appearance, and development period (number of days until final apothecium appeared). Three variables were used for our data analysis. The first two were the total number of 
initials and total number of apothecia produced in each light-temperature-moisture treatment. Total number of initials in a crisper was the sum of all dead initials, the live initials, and initials that formed apothecia for the entire experimental period. Total number of apothecia were the sum of dead and live apothecia for the entire experimental period. The third variable was the cumulative apothecia, defined as the sum of dead and live apothecia cumulative to a given day. At 150 days of low light intensity, apothecium production was still proceeding in those treatments at the $6^{\circ} \mathrm{C}$ level. The experiments at high light intensity were completed at 90 days, because sclerotia in these treatments completed apothecium production by this time.

Data analysis. The total number of apothecia produced in each light-temperature-moisture treatment were analyzed with two-factor or three-factor analysis of variance (PROC ANOVA, Statistical Analysis System, Cary, NC) to determine if the effect of any of the factors was significant. Data of the 25 and $30^{\circ} \mathrm{C}$ treatments were used to examine the two-way or three-way interactions among light, temperature, and moisture using PROC ANOVA. No significant differences were found between results of repeated experiments and, therefore, data were pooled for variance analysis.

Cumulative degree day (14) was used to quantify the relationship between degree days and cumulative apothecia produced. The degree day, $D_{i}$, was calculated by $D_{i}=$ $t_{i}$, for $j=1$ to $i$, in which $t_{i}$ was the average temperature of the $i$ th day. The cumulative apothecia on the $i$ th day consisted of the total number of apothecia produced from the first day of the chamber experiment to the $i$ th day. The average daily temperature, $t_{i}$, was the weighted sum of day and night temperatures in the chamber, which was calculated by (day temperature $x$ daytime hours + night temperature $\times$ nighttime hours)/24. At low light intensity, the difference between day and night temperatures was $2.5^{\circ} \mathrm{C}$ and, at high light intensity, it was $3^{\circ} \mathrm{C}$. The average daily temperatures at low light intensity and high light intensity were calculated as $\left(t_{0} \times 14+\left[t_{0}-2.5\right]\right.$ $\times 10) / 24$ and $\left(t_{0} \times 14+\left[t_{0}-3.5\right] \times 100\right) / 24$, respectively. In this equation, $t_{0}$ was the daytime temperature for a given temperature treatment and $t_{0}=6,12,18,25$, and $30^{\circ} \mathrm{C}$ under low light intensity or 10,15 , 20,25 , and $30^{\circ} \mathrm{C}$ under high light intensity, respectively. The numbers of 10,14 , and 24 in the equation refer to nighttime hours, daytime hours, and hours per day, respectively.

For example, at day 38, the cumulative number of apothecia for the treatment at moisture level I, low light intensity, and $30^{\circ} \mathrm{C}$ was two. The corresponding cumulative degree days were $38(30 \times 14+27.5 \times$ $10) / 24=1,100$ cumulative degree days. The advantage in using the degree day concept for this analysis is the standardization and quantification of the effects of different temperature treatments.

\section{RESULTS}

First initial appearance, first apothecium appearance, and development period. For the treatments of the same temperatures and light intensity, there were no significant differences among the three moisture levels in following three incubation variables: days of first initial, days of first apothecium appearance, and period of development of a sclerotium, which is defined as the period from production of first initial to production of final apothecium. Mean values of three moisture treatments at different temperatures and light intensities are presented in Figure 1. Apothecium production was poor at the low light intensity and low temperature $\left(6^{\circ} \mathrm{C}\right)$ combination. At that combination, the first initials appeared at 80 days and first apothecia appeared 130 days after incubation began. At 150 days, when the low light intensity experiments were terminated, only a few initials had produced apothecia at $6^{\circ} \mathrm{C}$ (Fig. 1A). Under high light intensity, the first initial appeared at 10 days after incubation began (Fig. 1B). At both light intensities, as temperature increased, days for apothecium production became shorter. It took 2 days for the initials to develop into apothecia at high light intensity but took more than 7 days at low light intensity. The period for initials to
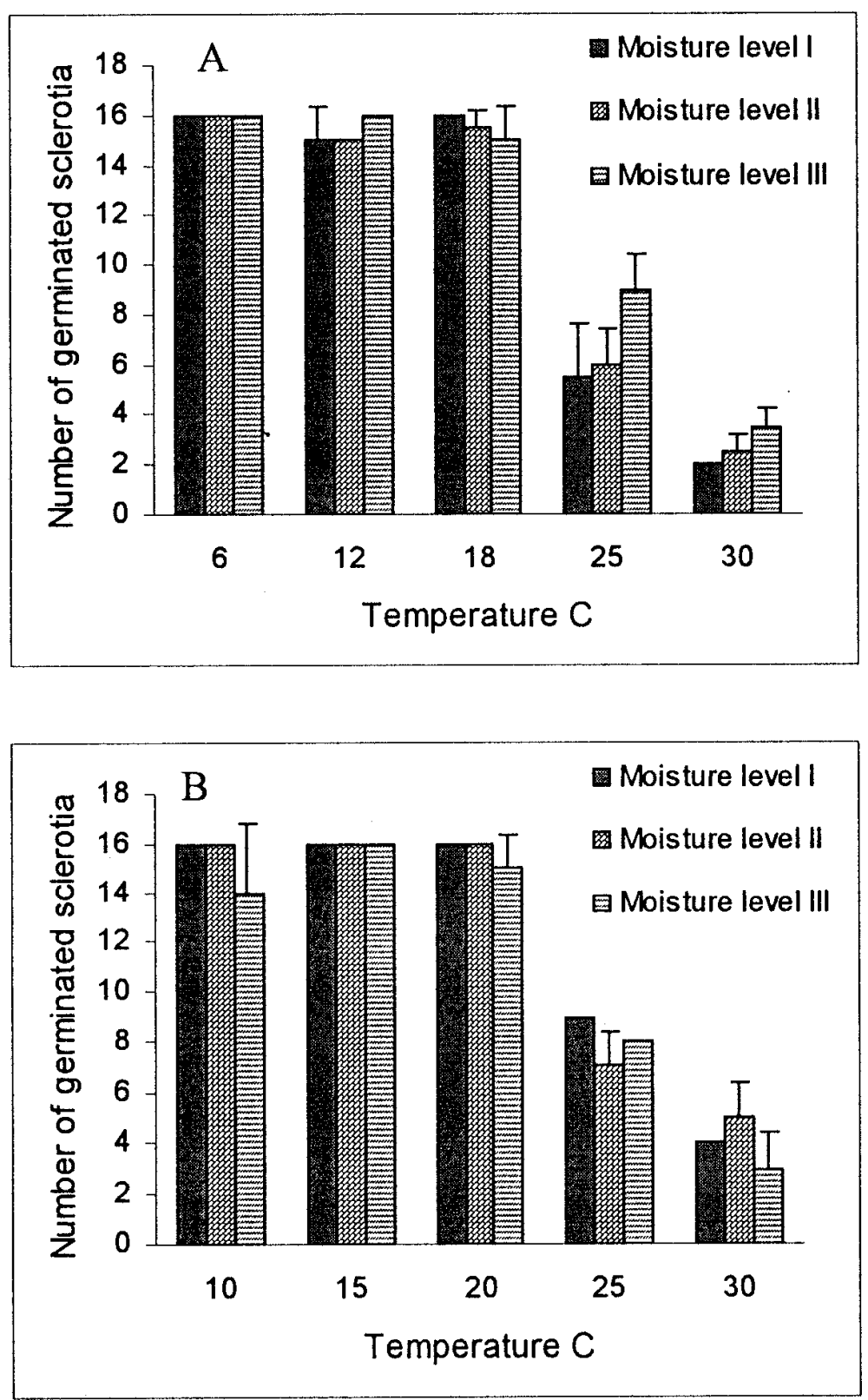

Fig. 2. Total numbers of germinated sclerotia of Sclerotinia sclerotiorum per crisper under different light-moisture-temperature combinations in experiments at (A) low and (B) high light intensity. Values are the means plus the standard error of the means. Standard errors were zero for some treatments. Note that standard error $(\mathrm{SE})=0$ for some treatments because all sclerotia were germinated. 
develop into apothecia was substantially longer for all treatments exposed to low light intensity than those to high light intensity (Fig. 1).

Effects on percentages of sclerotium carpogenic germination and initial and apothecium production. The effects of temperature were greater on carpogenic germination when the temperature was higher than $18^{\circ} \mathrm{C}$ (Fig. 2). The number of germinated sclerotia showed a substantial decrease at 25 and $30^{\circ} \mathrm{C}$ under both light intensities. Under low light intensity, more initials were produced at the lower temperature regime, 6 to $12^{\circ} \mathrm{C}$ (Fig. $3 \mathrm{~A}$ ), and less than half of initials developed into apothecia at $25^{\circ} \mathrm{C}$. At high light intensity, the highest number of initials was at $20^{\circ} \mathrm{C}$ (Fig. 3B), and more than $80 \%$ of initials developed into apothecia at $25^{\circ} \mathrm{C}$. Apothecium production varied under different temperatures and there were different optimal temperatures for apothecium production for different light intensities. Most apothecium production under low light intensity occurred in the 12 to $18^{\circ} \mathrm{C}$ range and high light intensity at $20^{\circ} \mathrm{C}$ (Fig. 4).

There were no significant differences between the two light intensities in the number of sclerotia germinated (Fig. 2A and $\mathrm{B}$ ). However, light intensity significantly affected initial and apothecium production. Under low light intensity, the total number of initials was greater than that produced under high light intensity (Fig. 3 ), but only part of those initials turned to apothecia (Figs. 3A and 4A). Under high light intensity, most of the initials turned to
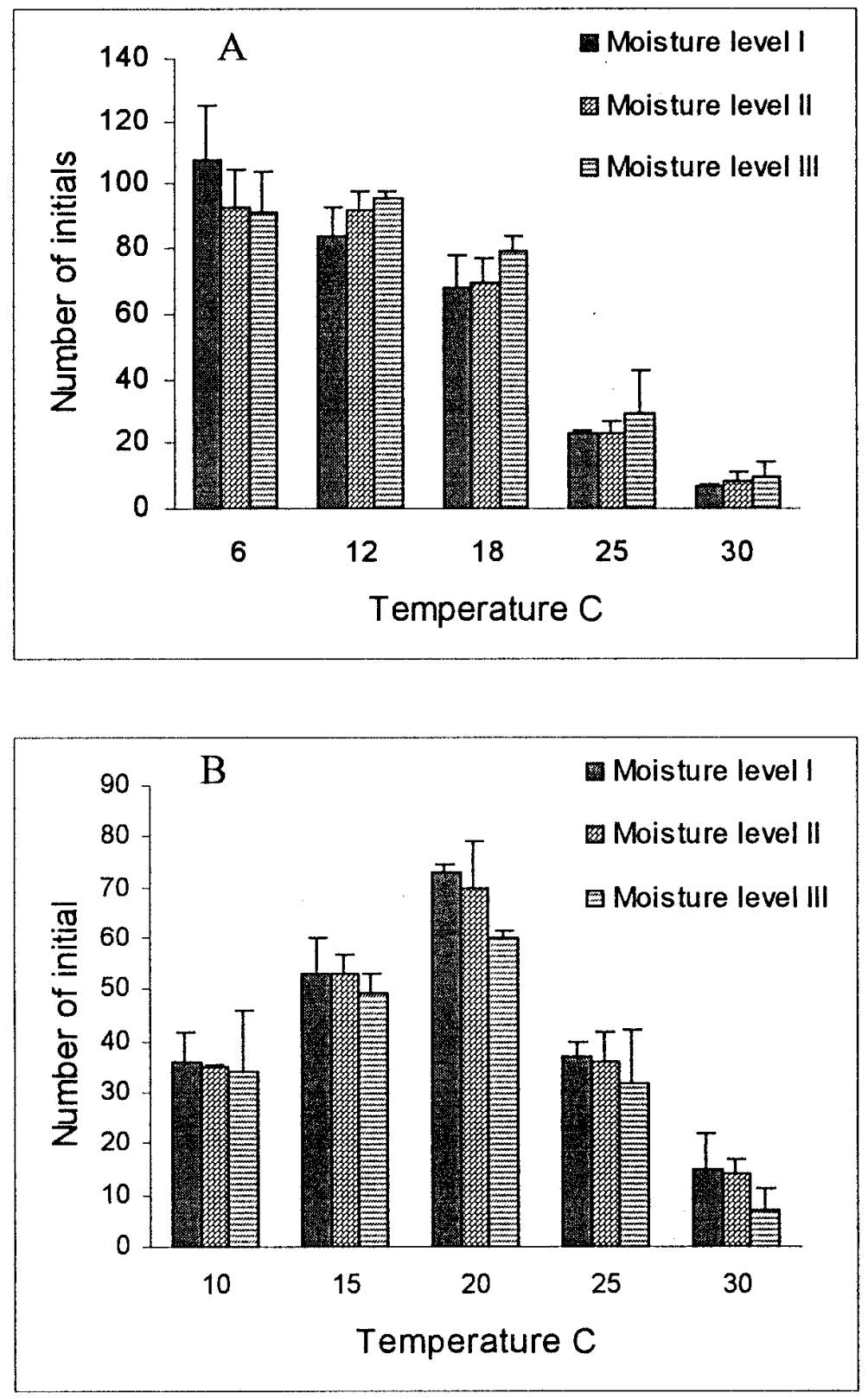

Fig. 3. Total numbers of initials produced by sclerotia of Sclerotinia sclerotiorum per crisper under different light-moisture-temperature combinations in experiments at (A) low and (B) high light intensities. Values are the means plus the standard error of the means.

apothecia (Figs. 3B and 4B). In addition to the data reported in Figures 1 to 4 , we observed that, under low light intensity, the initials were long and thin whereas, at high light intensity, the initials were short and thick. Apothecia were larger at high light intensity than that at low light intensity. At low light intensity, the sizes of the apothecia produced at the three moisture conditions were similar but, at high light intensity, the sizes of apothecia produced at moisture level III were smaller than those produced at the other two moisture levels. Within a crisper, greater variations in number of initials or apothecia per sclerotium were found in treatments of low light intensity than high light intensity. Under high light intensity, a germinated sclerotium consistently produced two to eight initials or apothecia, depending on temperaturemoisture combination.

The effect of moisture treatment on apothecia production was not as significant as that of temperature or light intensity treatment. However, its effect interacted with light intensity. Under high light intensity and optimum temperature $\left(20^{\circ} \mathrm{C}\right)$, significantly $(P<0.05)$ more apothecia were produced at moisture levels I and II than at moisture level III (Fig. 4B). The trend was also present in other temperature treatments. Under low light intensity, there was a trend that apothecia were produced most at moisture level III (Fig. 4A). These results suggest that sclerotia can produce apothecia at a wide moisture range at low light intensity; however, at high light intensity, sclerotia can produce more apothecia overall at high moisture levels for most temperature-moisture combinations.

Interactions. Statistical tests show that the differences among treatments of the two repeated experiments were not significant either under low or high light intensity. The SE for each treatment between the two repeated experiments is presented in Figures 1 to 4 . Therefore, the averages of the two repeated experiments were used for further statistical analysis to examine the effects of temperature, moisture, and their interactions. Temperature 25 and $30^{\circ} \mathrm{C}$ were used in both of the light intensities; therefore, the data of the two temperature treatments were used to test the effect of light intensity and also the interrelationship between the three factors. Two-factor (temperature-moisture) results of ANOVA showed that, under both low and high light intensities, effects of temperature on apothecium production were significant at the level $P<0.0001$. The effects of moisture were significant at the level of $P<0.0001$ under low light intensity and at the level of $P<0.003$ under high light intensity. At both light intensities, the interactive effects of temperaturemoisture were not significant. Combining data of all experiments for three-factor (light-temperature-moisture) ANOVA showed that effects of light intensity and 
temperature were significant $(P<0.0001)$, the interactive effects of temperature-light were significant $(P<0.001)$, the interactive effects of temperature-moisture were not significant, the interactive effects of light intensity-moisture were significant at the level of $P<0.03$, and the three-way interaction of temperature-moisture-light intensity was not significant (Table 1).

Regression between degree day and cumulative apothecia. The quantitative relationships between cumulative apothecia and degree days for six light-moisture combinations is shown (Fig. 5). Relationships between cumulative apothecia and degree days under low light intensity (Fig. 5A-C) and under high light intensity (Fig. 5D-F) are indicated. The relationships between cumulative apothecia and degree days under three different moisture conditions had similar trends, as indicated by the signs of the regression coefficients. Under low light intensity, the first order regression coefficients were all negative and second order all positive for all moisture levels (Fig. 5A-C). The difference between the two light intensities is great. Under high light intensity, both first and second orders of regression coefficients were positive (Fig. 5D-F), indicating stronger response of apothecium production to degree days when light intensity is high. Under low light intensity, regardless of moisture level, the apothecium production began at about 760 degree days and ceased at 1,720 days (Fig. 5A-C). Production began at about 160 cumulative degree days and ceased at about 900 degree days at high light intensity (Fig. 5D-F).

\section{DISCUSSION}

Our study found that the fungus S. Sclerotiorum used in this experiment had a higher temperature range for apothecium production than reported by Abawi and Grogan 25 years ago (1). They reported that the numbers of apothecia produced at 20 and $25^{\circ} \mathrm{C}$ were small, and that the fungus would not produce apothecia at $30^{\circ} \mathrm{C}$ (1). In our experiment, sclerotia still produced apothecia at $30^{\circ} \mathrm{C}$, and the number of apothecia produced at $25^{\circ} \mathrm{C}$ was substantial, especially under high light intensity. Our low light intensity (80 to $90 \mathrm{~mol}$ $\mathrm{m}^{-2} \mathrm{~s}^{-1}$ inside the crispers) was about the same intensity that Abawi and Grogan used; however, the populations of S. sclerotiorum used in our study may be different from those of their study (1) in apothecium production. The difference might be in temperature requirements for sclerotium germination among $S$. sclerotiorum populations from different geographical origins, which is consistent with previous reports $(9,10)$. Sclerotinia stem rot of soybean disease has emerged in areas further south of its original endemic environment in the north-central soybean production region, which suggests possible adoption of isolates to warmer temperatures or possible introduction of isolates from warmer areas. In light of findings from this study, we cannot exclude the possibility.

Our study shows (Fig. 4) that sclerotia can produce apothecia in a wide range of moisture conditions and demonstrates the interaction between light intensity and moisture affected apothecium production (Table 1). For treatments at low light intensity under $25^{\circ} \mathrm{C}$, a lower moisture of sand (level III) produced the highest number of apothecia (Fig. 4A). In contrast, under high light intensity, the highest moisture level (level I) was better for apothecia production than moisture level III (Fig. 4B). Our results suggest that, if light intensity is high and the soil is relatively dry in a soybean field, the development of sclerotia stem rot would be reduced. Our data also suggest that, before the canopy closes, high soil moisture is important for apothecium production. During this period, precipitation could produce an environment favorable for apothecia production. However, after canopy closure, the relative importance of soil moisture for apothecium production may be reduced due to the reduction in light intensity, and temperature becomes more important.

In the regression equations on cumulative apothecia and cumulative degree days for different moisture levels, the deviation between the expected and observed values increased as cumulative degree days increased. For low light intensity (Fig. 5A$\mathrm{C})$, the observed number of cumulative
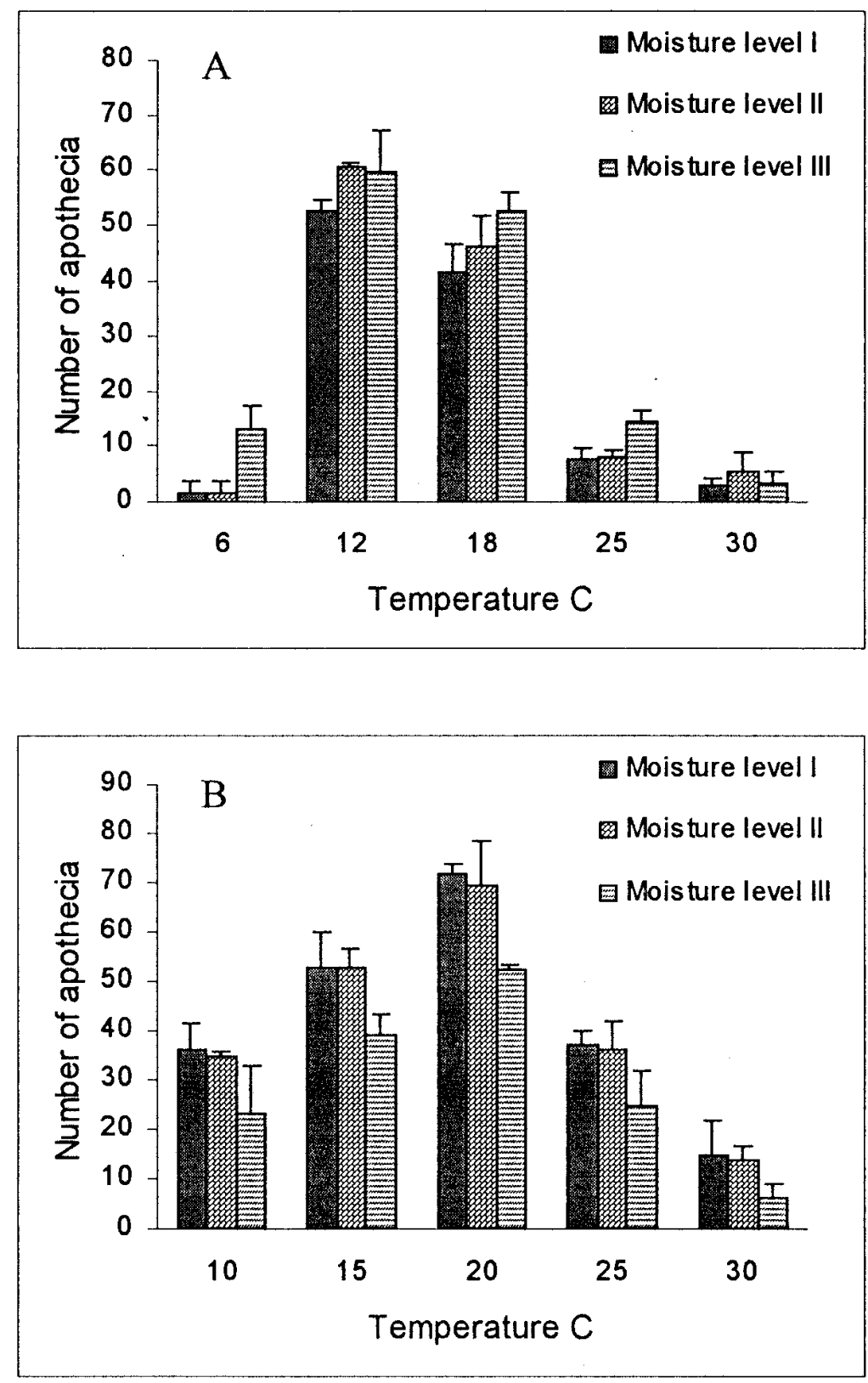

Fig. 4. Total numbers of apothecia produced by sclerotia of Sclerotinia sclerotiorum per crisper under different light-moisture-temperature combinations in experiments at (A) low and (B) high light intensity. Values are the means plus the standard error of the means. 
Table 1. Analysis of variance (ANOVA) of carpogenic germination of sclerotia of Sclerotinia sclerotiorum under different moisture levels, temperatures, and light intensities ${ }^{\mathrm{a}}$

\begin{tabular}{|c|c|c|c|c|c|}
\hline Source & df & SS & Mean square & F value & $P>F$ \\
\hline \multicolumn{6}{|c|}{ Low light intensity ${ }^{b}$} \\
\hline $\mathrm{T}$ & 4 & 37.07 & 9.27 & 79.71 & 0.0001 \\
\hline M & 2 & 4.48 & 2.24 & 19.28 & 0.0001 \\
\hline $\mathrm{T} \times \mathrm{M}$ & 8 & 0.39 & 0.05 & 0.42 & 0.8936 \\
\hline \multicolumn{6}{|c|}{ High light intensity ${ }^{c}$} \\
\hline $\mathrm{T}$ & 4 & 60.80 & 15.20 & 257.81 & 0.0001 \\
\hline M & 2 & 1.04 & 0.52 & 8.83 & 0.0029 \\
\hline $\mathrm{T} \times \mathrm{M}$ & 8 & 0.65 & 0.08 & 1.38 & 0.2813 \\
\hline \multicolumn{6}{|l|}{ Combined $^{\mathrm{d}}$} \\
\hline $\mathrm{T}$ & 1 & 4.33 & 4.33 & 58.29 & 0.0001 \\
\hline M & 2 & 0.40 & 0.20 & 2.71 & 0.1069 \\
\hline $\mathrm{L}$ & 1 & 5.33 & 5.33 & 71.81 & 0.0001 \\
\hline $\mathrm{T} \times \mathrm{M}$ & 2 & 0.002 & 0.001 & 0.02 & 0.9846 \\
\hline $\mathrm{M} \times \mathrm{L}$ & 2 & 0.73 & 0.36 & 4.89 & 0.0279 \\
\hline $\mathrm{T} \times \mathrm{L}$ & 1 & 1.29 & 1.29 & 17.42 & 0.0013 \\
\hline $\mathrm{T} \times \mathrm{M} \times \mathrm{L}$ & 2 & 0.07 & 0.034 & 0.45 & 0.6469 \\
\hline
\end{tabular}

a Mean values of the two repeated experiments were used for the analyses; SS = sum of square; T, M, and $\mathrm{L}$ are temperature, moisture, and light intensity, respectively.

b Two-factor ANOVA for the experiments at low light intensity.

c Two-factor ANOVA for the experiments at high light intensity.

d Three-factor ANOVA for the data from two temperature levels $\left(25\right.$ and $\left.30^{\circ} \mathrm{C}\right)$, three moisture treatments, and two light intensity treatments.
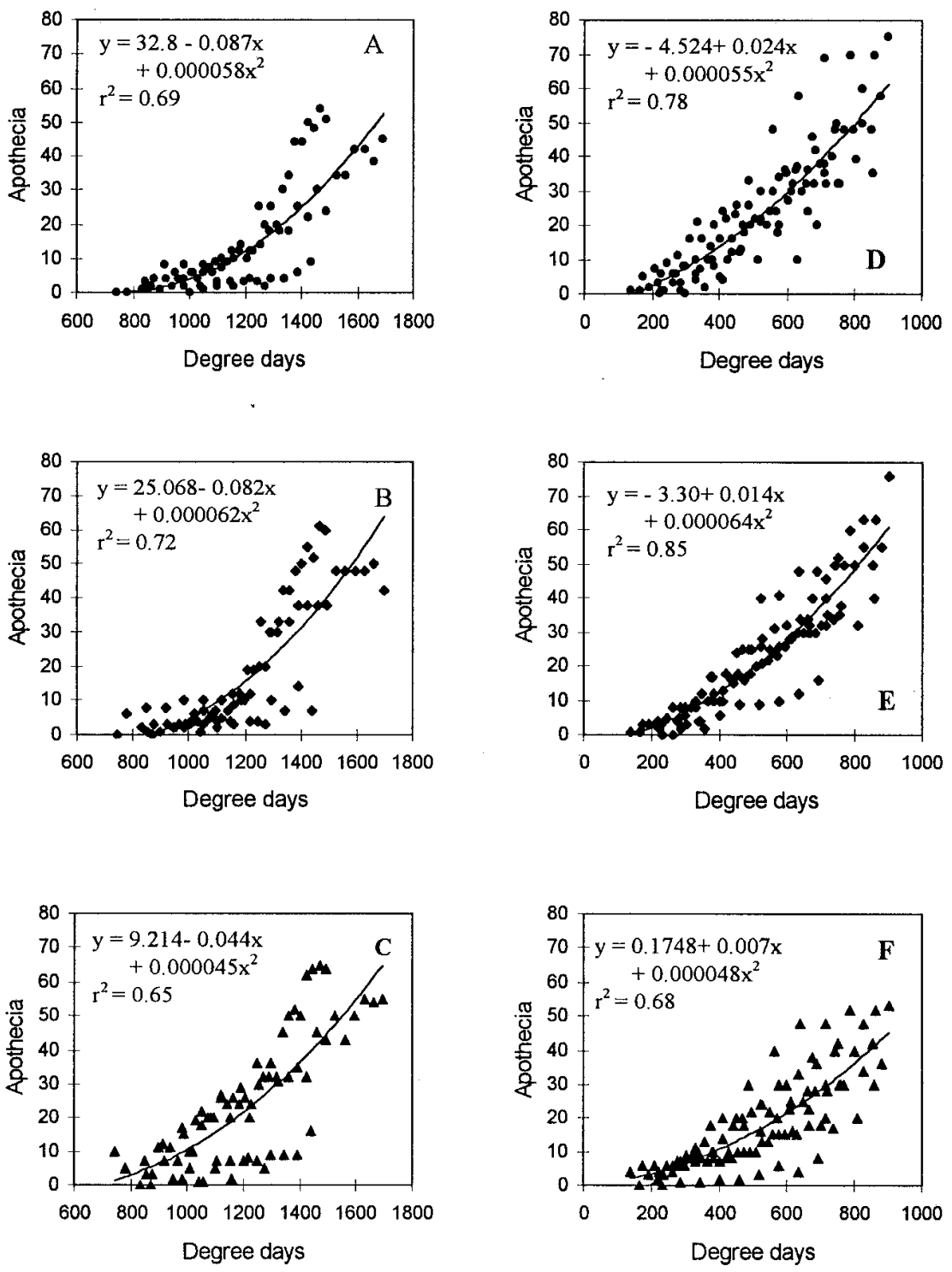

Fig. 5. Regression equations of cumulative degree days and cumulative apothecia of Sclerotinia sclerotiorum. (A), (B), and (C): two replicates of the three moisture levels I, II, and III under low light intensity; (D), (E), and (F): three moisture levels under high light intensity. apothecia produced between 760 and 1,200 degree days is close to that predicted by the regression equations. However, as degree days approach 1,400 , the deviation between observations and prediction becomes larger. This trend holds true under high light intensity as well (Fig. 5D-F). This means that the predicted values of the regression equations are in line with the observations when the number of cumulative degree days is low. Similar results were obtained by converting the data to physiological days (28) developed from the original degree day concept. In using the concept of cumulative degree days for prediction, we need to make clear the effective temperature range for apothecia production. For example, in the regression equations of Figure 5A to $\mathrm{C}$, calculations were based on a maximum temperature of $30^{\circ} \mathrm{C}$ and the minimum temperature of $3.5^{\circ} \mathrm{C}$. If temperatures are higher than $30^{\circ} \mathrm{C}$ or lower than $3.5^{\circ} \mathrm{C}$, the regression equations may not produce good predictions.

The fact that apothecium production requires only 160 degree days suggests that, before the soybean field is covered by the canopy, sclerotia on the surface of the soil may germinate if the soil is sufficiently moist. In fields, the natural light may affect apothecium production differently than light in growth chambers. It is possible that natural light has higher intensity and a greater effect on apothecium production compared with artificial light. In the northcentral region, 160 degree days are readily achieved prior to canopy closure. If the average temperature is $20^{\circ} \mathrm{C}$, only 10 days are needed to reach 160 degree days. Our regressions suggest that, with adequate precipitation to saturate soil, apothecia may appear in 10 days under average daily temperatures of about $20^{\circ} \mathrm{C}$. Our study showed that degree days might be a useful way for predicting apothecium production However, in establishing models for field prediction, we should note that light intensity may vary significantly on a daily bases, which could affect apothecia production. To characterize the effects of daily average light intensity in a soybean field for quantitative prediction of apothecia production requires further study.

\section{ACKNOWLEDGMENTS}

We thank S. Sanogo and F. Workneh for presubmission review and P. Lundeen for assistance.

\section{LITERATURE CITED}

1. Abawi, G. S., and Grogan, R. G. 1975. Source of primary inoculum and effects of temperature and moisture on infection of beans by Whetzelinia sclerotiorum. Phytopathology 65:300-309.

2. Abawi, G. S., and Grogan, R. G. 1979. Epidemiology of diseases caused by Sclerotinia sclerotiorum. Phytopathology 69:899-904.

3. Blad, B. J., Steadman, J. R., and Weiss, A. 1978. Canopy structure and irrigation influence white mold disease and microclimate of dry edible beans. Phytopathology 68:1431-1437.

4. Boland, G. J., and Hall, R. 1987. Epidemiol- 
ogy of white mold of white bean in Ontario. Can. J. Plant Pathol. 9:218-224.

5. Caesar, A. J., and Pearson, R. C. 1983. Environmental factors affecting survival of ascospores of Sclerotinia sclerotiorum. Phytopathology 73:1024-1030.

6. Doupnik, B., Jr. 1993. Soybean production and disease loss estimates for north central United States from 1989 to 1991. Plant Dis. 77:1170-1171

7. Grau, C. R. 1988. Sclerotinia stem rot of soybean. Pages 47-48 in: Soybean Diseases of the North Central Region. T. D. Wyllie and D. H. Scott, eds. APS Press, St. Paul, MN.

8. Harada, Y., Tanba, H., and Watanabe, H. 1974. Cultural studies on apothecial formation in Sclerotinia sclerotiorum. I. Germination test of sclerotia produced at different temperatures and aged for various periods. Bull. Fac. Agric. Hirosaki Univ. 22:37-43.

9. Huang, H. C., and Kozub, G. C. 1991. Temperature requirements for carpogenic germination of sclerotia of Sclerotinia sclerotiorum isolates of different geographic origin. Bot. Bull. Acad. Sin. 32:279-286.

10. Huang, H. C., and Kozub, G. C. 1993. Influence of inoculum production temperature on carpogenic germination of sclerotia of Sclerotinia sclerotiorum. Can. J. Microbiol. 39:548-550.

11. Keay, M. A. 1939. A study of certain species of the genus Sclerotinia. Ann. Appl. Biol. 26:227-246.

12. Letham, D. B. 1975. Simulation of light of apothecial initial development of Sclerotinia sclerotiorum in soil. Soil Biol. Biochem. 8:385-389.
13. Newton, H. C., and Sequeira, L. 1972. Ascospores as the primary infection propagule of Sclerotinia sclerotiorum in Wisconsin. Plant Dis. Rep. 56:798-802.

14. Nuttonson, M. Y. 1956. A Comparative Study of Lower and Upper Limits of Temperature in measuring the Variability of Day-Degree Summations of Wheat, Barley, and Rye. American Institute of Crop Ecology, Washington, D.C.

15. Phillips, A. J. L. 1986. Carpogenic germination of sclerotia of Sclerotinia sclerotiorum: A review. Phytophylactica 19:279-283.

16. Purdy, L. H. 1956. Factors affecting apothecial production by Sclerotinia sclerotiorum. Phytopathology 46:409-410.

17. Purdy, L. H. 1979. Sclerotinia sclerotiorum: History, diseases and symptomatology, host range, geographic distribution, and impact. Phytopathology 69:875-880.

18. Schwartz, H. F., and Steadman, J. R. 1978. Factors affecting sclerotium populations of and apothecial production by Sclerotinia sclerotiorum. Phytopathology 68:383-388.

19. Schwartz, H. F., Steadman, J. R., and Coyne, D. P. 1978. Influence of Phaseolus vulgaris blossoming characteristics and canopy structure upon reaction to Sclerotinia sclerotiorum. Phytopathology 68:465-470.

20. Steadman, J. R. 1983. White mold-a serious yield-limiting disease of bean. Plant Dis. 76:346-350.

21. Sun, P., and Yang, X. B. 1997. Temperature and moisture effects on apothecium production of Sclerotinia sclerotiorum. (Abstr.) Phytopathology 87(Suppl.):S95.

22. Teo, B. K., and Morrall, R. A. A. 1985. Influ- ence of matric potentials on carpogenic germination of sclerotia of Sclerotinia scle rotiorum. I. Development of an inclined box echnique to observe apothecium production. Can. J. Plant Pathol. 7:358-364.

23. Tu, J. C. 1989. Modes of primary infection caused by Sclerotinia sclerotiorum in navy bean. Microbios 57:85-91.

24. Weiss, A., Kerr, E. D., and Steadman, J. R. 1980. Temperature and moisture inferences on development of white mold disease (Sclerotinia sclerotiorum) on Great Northern beans. Plant Dis. 64:757-759.

25. Williams, J. R., and Stelfox, D. 1980. Influence of farming practices in Alberta on germination and apothecium production of sclerotia of Sclerotinia sclerotiorum. Can. J. Plant Pathol. 2:169-172.

26. Wrather, J. A., Anderson, T. R., Arsyad, D. M., Gai, J., Ploper, L. D., PortaPuglia, A. Ram, H. H., and Yorinori, J. T. 1997. Soybean disease loss estimates for the top 10 soybean producing countries in 1994. Plant Dis. 81:107-110.

27. Yang, X. B., Lundeen, P., and Uphoff, M. D. 1999. Soybean varietal response and yield loss caused by Sclerotinia sclerotiorum. Plant Dis. 83:456-461.

28. Yang, X. B., Royer, M. H., Tschanz, A. T., and Tsai, B. Y. 1990. Analysis and quantification of soybean rust epidemics from seventy-three sequential planting experiments. Phytopathology 80:1421-1427.

29. Yang, X. B., Workneh, F., and Lundeen, P. 1998. First report of sclerotium production by Sclerotinia sclerotiorum in soil on infected soybean seeds. Plant Dis. 82:264. 